\title{
Relación prensa-Estado, consideraciones hacia la regulación de la publicidad oficial en México. Estudio regional
}

\author{
Press-State relations in Mexico, considerations towards the \\ regulation of official advertising: Regional study
}

Patricia Maldonado Pérez maldonadoperez11@hotmail.com

http://orcid.org/0000-0002-7656-190X

Universidad Autónoma del Estado de México (México)

\section{Resumen}

La decisión de la Suprema Corte de Justicia de la Nación de obligar al Congreso mexicano a crear una ley que regule la publicidad oficial en el país antes del 30 de abril de 2018 representa la oportunidad de acabar con la asignación discrecional histórica de recursos públicos a medios de comunicación. Sin embargo, la nueva legislación debe abarcar, de la gama de propuestas, las particularidades de la relación prensa-Estado mediante la cual se han tejido las más finas redes de clientelismo y corrupción.

En este estudio se presenta el caso del Estado de México, reducto del partido hegemónico mexicano, donde el clientelismo como estrategia política ha infiltrado a la prensa con tácticas patentes y otras ocultas, pero ambas ilegales, hacerla un instrumento de control, conservación y expansión de poder. Se presentan testimonios de periodistas de referencia conjuntamente con análisis de contenido y reportes de gastos oficiales, vía Transparencia Pública, como 
evidencia al fenómeno del clientelismo mediático en un periodo no electoral, en contraste con la mayoría de estudios sobre clientelismo.

Palabras clave: Publicidad discrecional; clientelismo mediático; relación prensa-Estado; Estado de México.

\section{Abstract}

The decision of the Supreme Court of Justice of the Nation to obligate the Mexican Congress to create a law that regulates the official publicity in the country before April 30, 2018 represents the opportunity to end the historical discretionary allocation of public resources to media Communication. However, the new legislation must cover, from the range of proposals; the particularities of the Press-State relationship through which the finest networks of clientelism and corruption have been woven.

This study presents the case of the State of Mexico, the stronghold of the Mexican hegemonic party, where clientelism as a political strategy has infiltrated the press with tactics and other hidden, but both illegal, make it an instrument of control, conservation and expansion of power. Testimonies from leading journalists are presented together with content analysis and official expenditure reports, via Public Transparency, as evidence of the phenomenon of media clientelism in a non-electoral period, in contrast to most studies on clientelism.

Keywords: Official advertising; media clientelism; press-State relationship; Mexico state.

La historia de la relación Estado-prensa en México ha sido un tema recurrente de estudio por parte de la academia mexicana a partir su perversidad (Trejo, 1995) ya que el vínculo parte del acceso a recursos públicos tangibles e intangibles con objetivos políticos, económicos y sociales (Fernández 1982; Trejo 1995-1996; Carreño, 2000; Scherer y Monsiváis, 2003; Rodríguez Castañeda, 1999; Avilés 2007; Rodríguez Munguía, 2007). Alrededor de tal binomio se han formado redes de lucro que desembocan en abuso de funciones y atribuciones públicas, desvío de recursos, tráfico de influencias, colusión y soborno, entre otras formas de corrupción.

Aquel vínculo que se acrecentó 16 años antes del inicio de la Revolución Mexicana con el patrocinio de la primer rotativa en México en la que se imprimió El Imparcial (1896), a cargo del 
entonces secretario de Hacienda José Ives Limantour (Fernández, 1982), significó el paso a la industrialización de la prensa pero un retroceso a su autonomía funcional pues mientras en el escenario internacional la masificación de los medios impresos sirvió para independizarse del poder político con la inclusión de la publicidad comercial o privada (Carreño, 2000; Benavides, 2009), en la prensa mexicana sucedió al contrario, al darse pauta a la subsecuente protección económica desde el presupuesto público.

En tal circunstancia, la prensa mexicana se ha caracterizado por sus contenidos a base de dichos (Lichfield, 2000), acciones e imágenes de miembros de la clase política alejándose de su función social de informar de los sucesos de la vida cotidiana que trascienden a la formación de ideas y opiniones de la sociedad. A la par, se ha venido encubriendo información del quehacer político y/o propagando opiniones que le resultan favorables a sus objetivos (Trejo 1995; Avilés, 1999; Carreño, 2000; Scherer y Monsiváis, 2003; Rodríguez Castañeda, 1999; Rodríguez Munguía, 2007).

En esta dinámica han tenido participación directa de propietarios y directivos de medios y periodistas, ya sea por conveniencia o connivencia. En lo que corresponde a los dueños y/o directivos han desarrollado sus negocios informativos desde el ingreso que les significa acceder al presupuesto publicitario que en la mayoría de los casos rebasa el 60 por ciento de los ingresos totales de los medios, sin importar el tamaño, dimensiones, tiraje, distribución y circulación y desde luego, contenido.

Las relaciones personales han sido las que predominan en la asignación de recursos públicos tal cual sucedió con los medios de referencia de la Ciudad de México mediante la subvención de papel para imprimir, condonación de impuestos como luz eléctrica y pago de cuotas al IMSS, aparte de los créditos y demás apoyos intangibles fortalecidos con un marco legal débil y acomodaticio (Trejo, 1995; Carreño, 2000; Scherer y Monsiváis, 2003).

De mismo modo, directivos de medios y periodistas han hecho uso de las relaciones personales con sus fuentes de información o cercanía al poder político al tiempo que han recibido dinero de partidas presupuestales secretas y/o desconocidas además de disfrutar de un trato privilegiado de parte del poder político en el acceso a los servicios que proporciona el Estado y obsequios varios (Rodríguez Castañeda, 2007).

El objetivo subyacente en los medios de prensa es el acceso a recursos públicos para lograr presencia social y política. Un proceder manifiesto en la arbitrariedad, la ventaja ilegítima y la ausencia de ética semejante al patrón de control político extraoficial privilegiado por el partido hegemónico que gobernó a México 71 años continuos y que de nuevo lo administra para el periodo (2012-2018): el clientelismo. El clientelismo político consistente en la formación de un 
nexo entre un patrón y un cliente (de donde toma el nombre) con quien se intercambia asistencia oficial por apoyo político y votos.

En su traslación al ámbito de los medios, se descubre en la relación extraoficial que establecen medios de comunicación y periodistas con el poder político para el acceso a recursos públicos materiales (gasto oficial en publicidad, aportaciones económicas personales, obsequios, invitaciones, etcétera) e inmateriales (trámites y servicios oficiales) a cambio de cobertura informativa favorable pero además de una garantía tácita de cuidado y protección de la institución o del poder político y de quienes lo personifican (Maldonado, 2017).

Es desde la práctica del clientelismo mediático que las publicaciones noticiosas ceden espacio y jerarquía en el tratamiento informativo al poder político, desde luego con la consabida ventaja que esto les brinda especialmente a los propietarios de medios. En este contexto se haya como realidad fundamental la cantidad y características de la prensa mexicana sobre lo que se discurrirá a continuación.

\section{Métodos y materiales}

Para saber cuántas, cuáles y cómo son las publicaciones informativas impresas que hay en México, la Secretaría de Gobernación dispone del Padrón Nacional de Medios Impresos (PNMI), al que la inscripción es voluntaria. En tanto, el requisito de empadronamiento consiste en proporcionar una carta-protesta, elaborada por una empresa ajena al medio, con información básica sobre circulación, cobertura geográfica y perfil del lector del medio.

Sin embargo, esos datos de acceso público adolecen de corroboración por la propia Secretaría o alguna otra oficina, precisamente por la característica de voluntariedad. Esto hace que publicaciones como Hoy Estado, que se incluye en este estudio, exhiba en el PNMI un tiraje de 14 mil 750 ejemplares mientras que en la versión impresa publica que tiene un tiraje de 125 mil unidades.

EI PNMI está, por otro lado, rebasado en información disponible; basta contrastar su registro de medios con los que posee el Gobierno del Estado o ayuntamientos (de los que se hablará más adelante) disponibles desde sus portales en internet. Pero así como el PNMI es opcional, ha sido la entidad más conocida para el registro y consulta de medios escritos (Trejo, 2001; García, 2013), de ahí que la muestra de este estudio se estableció a partir de los medios con mayor circulación en cuatro de cinco regiones en que tradicionalmente se divide al Estado de México -el PNMI no contiene información de la Zona Sur: El Sol de Toluca, (Valle de 
Toluca), El Correo del Siglo XXI (Zona Norte), Adelante en la Noticia (Valle de México) y Hoy Estado de México (Zona Oriente).

En tal propósito, El Sol de Toluca es un periódico de la Organización Editorial Mexicana (OEM) antes cadena periodística García Valseca, propiedad del coronel José García Valseca, magnate de la prensa por su amistad con la familia del expresidente Manuel Ávila Camacho (1940-1946). En cuanto a El Correo del Siglo XXI, su propietario es el médico cirujano Uriel Marco Antonio Huitrón Bravo. La familia Huitrón ha participado de manera activa en las actividades políticas, especialmente del Norte del Estado de México y el propio Marco Antonio Huitrón ha ocupado cargos públicos en Atlacomulco con miras a ser el alcalde.

Por lo que respecta a Adelante en la Noticia vio la luz con la nota del último informe del exgobernador Alfredo Baranda García quien solo duraría en el cargo dos años para cederlo a Ignacio Pichardo Pagaza, el gobierno de auge de esta publicación pues consiguió replicarse en los estados circunvecinos de Hidalgo, Morelos, Guerrero y el Distrito Federal. En último lugar, Hoy Estado, surgió en Ecatepec, en 2010, cuando el gobernador del Estado de México, Eruviel Ávila Villegas (2012-2017) ocupaba por segunda ocasión la presidencia municipal. El presente análisis se realiza en periodo no electoral precisamente durante el gobierno de Eruviel Ávila; transcurre del primero de abril de 2013 a marzo 31 de 2014 para completar un año sin calendario electoral ni con la planeación presupuestal que suelen acompañar los tres primeros meses de una administración, al igual que las entrevistas a periodistas de referencia y las solicitudes de gasto publicitario.

Con respecto a lo antes planteado, el estudio de la relación histórica entre sistemas de medios y sistemas políticos es visto por Hallin y Mancini (2004) a partir de la propiedad de los medios de comunicación; la forma en que estos se comercializan, el grado de intervención política de que son objeto y el nivel de paralelismo político en sus contenidos. Su propuesta se corrobora en el escenario mexicano y mexiquense en cuanto a que el sistema político domina al sistema de medios y por lo mismo denota sus formas y modos. No obstante, el estudio que aquí tiene lugar descubre al clientelismo mediático como maniobra del poder político en su sometimiento de la prensa mexiquense.

El clientelismo tiene su antecedente en la economía de crédito e intereses con la figura de un patrón que presta dinero a un cliente y por ello obtiene ganancias (Combes, 2011) y su estudio amplía al ámbito de la Sociología, la Antropología y en la Política a lo electoral (Schröter, 2010).

Emmanuel Phoh (2005) advierte que el clientelismo se dilucida en sus más remotos antecedentes de organización de la sociedad basada en el centralismo: en la época de las 
etnias quien tenía el control era un jefe supremo; durante en la Colonización española, el Señorío jurisdiccional y, más adelante, en las guerras de Independencia, la Corona española y/o oligarquías.

Posteriormente, la segunda mitad del siglo XX, el poder político en los países de la región estuvo a cargo de un dictador o presidente, dictador o partido, aunque la preeminencia del clientelismo se observa en la postrevolución con dos sucesos que darían forma al sistema político mexicano, desde la perspectiva de Daniel Cosío (1972): por una parte, el nacimiento de una Constitución que privilegiaba la función del presidente de la república sobre los demás poderes y, por la otra parte, la creación de un partido político principal, asociado a la clase política dominante o su equivalente, al poder político dirigente de la actividad social y con la mayor influencia social.

Tras la Revolución Mexicana aquel centralismo se propagaría con el auxilio de los llamados caciques y caudillos quienes, en su condición de militares y patriarcas, atendieron a los propósitos de expansión de poder se permitieron amasar fortunas al tiempo de someter a la gente necesitada (Roniger, 1994).

Es pues la estructura social histórica de México, similar a la del resto de América Latina (Phoh, 2005), la que ha diferenciado de manera sustancial el desarrollo de la prensa o sistema de medios de comunicación. En esta región, la prensa definió sus relaciones a partir de beneficios personales o de grupo de modo permitiendo implícitamente que los medios crecieran fuera de los parámetros instituidos por el marco legal y desarrollar conglomerados tanto de medios impresos como electrónicos (Guerrero y Márquez, 2014).

El clientelismo ha estado subyacente en el proceso de configuración de los medios pero también de su operatividad ya que interviene, directa o indirectamente, en los procesos de selección, creación y jerarquización de la información como enseguida se evidenciará.

\section{Hallazgos}

El eje de la prensa mexiquense es el acceso a los recursos públicos. El periodo de gobierno de Eruviel Ávila (2012-2017), el presupuesto en materia de publicidad, exclusivo para la prensa, reporta la preferencia en la asignación de recursos a 19 publicaciones: Adelante en la Noticia, Diario de México, Edomex al día, El Sol de Toluca, El Universal, Grupo Reforma, Hoy Caricatura, Hoy Estado, Impulso, La Crónica, La Jornada, Mi ambiente, Milenio, Ocho 
Columnas, OEM (Organización Editorial Mexicana), Ovaciones, Pódium, Portal y Puntual. De ese total, doce son medios de manufactura estatal y el resto de referencia nacional.

Por otro lado, nueve de esos medios recibieron más de un millón de pesos ininterrumpidamente: El Universal, Milenio y la OEM, seguidos de Adelante en la Noticia, La Crónica, Puntual y Ocho Columnas (con tres años consecutivos), Grupo Reforma y El Financiero (un año).

A su vez, el grupo que más dinero obtuvo en los años que comprenden 2012-2015 fue la OEM con seis millones 320 mil pesos, esto es, 100 mil más que Milenio y un millón 236 mil por arriba de El Universal, aunque a la OEM pertenecen los periódicos El Sol de Toluca y Extra de El Sol. Estos últimos recibieron recursos aparte por un millón 359 mil 440 pesos con 35 centavos (de 2012 a 2015) y 203 mil pesos en 2012, respectivamente.

En contraste, los medios impresos con menor recurso de procedencia oficial, corresponden a: La Opinión (13 mil pesos); El Gráfico Metropolitano (17 mil 400 pesos) y El Despertar del Sur (18 mil pesos) correspondiente, en los tres casos, a 2015. Del total de 63 publicaciones escritas que reciben publicidad del GEM, 15 (equivalentes al 23\%) carecen de registro oficial ante el PNMI de la Secretaría de Gobernación.

En relación con las publicaciones muestra en este estudio, Adelante en la Noticia se sitúa en primer lugar en ingresos estatales seguido de Hoy Estado de México (un millón 766 mil 400 pesos) y El Sol de Toluca. Por su parte, el periódico El Correo del Siglo XXI no está en la lista de clientes y en esta tampoco se refieren los periódicos agrupados en la organización Mac Ediciones y Publicaciones, S. A. de C. V. pero estos suman dos millones 784 mil pesos en los primeros cuatro años de gobierno, con base en una segunda respuesta de transparencia. En la siguiente tabla se muestra la distribución del gasto publicitario proveniente de Comunicación Social.

\begin{tabular}{lllll}
\hline Publicación & $\mathbf{2 0 1 3}$ & $\mathbf{2 0 1 4}$ & $\mathbf{2 0 1 5}$ & 2016 (agosto 15) \\
A Fondo & & $348,000.00$ & $104,400.00$ & \\
Adelante en la Noticia & $1,392,000.00$ & $1,160,000.00$ & $928,000.00$ & $580,000.00$ \\
Capital Toluca & & & $696,000.00$ & \\
Comunigrafic & $278,400.00$ & $278,400.00$ & $278,400.00$ & $186,760.00$ \\
Contragolpe Deportivo & & $261,000.00$ & $58,000.00$ & \\
Despertar del Sur & $32,480.00$ & $49,880.00$ & $18,000.00$ & $9,280.00$ \\
Diálogos Políticos & $278,400.00$ & $278,400.00$ & $278,400.00$ & $186,760.00$ \\
\hline
\end{tabular}




\begin{tabular}{|c|c|c|c|c|}
\hline Diario de México & $464,000.00$ & $429,200.00$ & $174,000.00$ & $232,000.00$ \\
\hline Diario Imagen & $696,000.00$ & $675,000.09$ & $450,000.05$ & $300,000.01$ \\
\hline Dinamik & & $46,400.00$ & & \\
\hline Edomex al Día & $348,000.00$ & $444,000.00$ & $333,000.00$ & $185,000.00$ \\
\hline El Nativo & & & & $2,320.00$ \\
\hline Edomex Comunidad de & & & $29,000.00$ & \\
\hline \multicolumn{5}{|l|}{ Vanguardia } \\
\hline El Diario & $696,000.00$ & $696,000.00$ & & \\
\hline El Economista & $116,000.00$ & $116,000.00$ & $116,000.00$ & \\
\hline El Espectador & $19,998.40$ & & & \\
\hline El Financiero & $403,927.78$ & $237,736.92$ & $1,404,868.99$ & \\
\hline El Gráfico & $840,000.00$ & $840,000.00$ & $470,000.00$ & \\
\hline El Gráfico Metropolitano & & & $17,400.00$ & \\
\hline El Informante & $390,000.00$ & $580,000.00$ & & \\
\hline El Pregón & & $46,400.00$ & & \\
\hline El Pulso & & $98,600.00$ & $236,640.00$ & $138,040.00$ \\
\hline El Mexiquense & $23,200.00$ & & & \\
\hline El Sol de Toluca & $301,835.20$ & $357,327.82$ & $401,933.43$ & $93,821.83$ \\
\hline El Universal & $1,160,000.00$ & $1,276,000.00$ & $1,160,000.00$ & \\
\hline En la Mira de México & $348,000.00$ & $348,000.00$ & $377,000.00$ & $203,000.00$ \\
\hline Es Opinión Mexiquense & & $27,840.00$ & $23,200.00$ & $23,200.00$ \\
\hline Exacto de México & $278,400.00$ & $278,400.00$ & $278,400.00$ & $160,080.00$ \\
\hline Excélsior & $150,000.00$ & $464,000.00$ & $464,000.00$ & \\
\hline Grupo Reforma & $178,872.00$ & $1,088,073.04$ & $19,627.20$ & \\
\hline Hechos & & $46,400.00$ & $58,000.00$ & $46,400.00$ \\
\hline Heraldo Estado & $140,517.20$ & $228,681.64$ & $185,000.00$ & $28,055.00$ \\
\hline Hoy Caricatura & $60,000.00$ & $64,000.00$ & $40,000.00$ & $16,000.00$ \\
\hline Hoy Estado de México & $450,000.00$ & $632,000.00$ & $580,000.00$ & $348,000.00$ \\
\hline Impulso & $928,400.11$ & $844,000.10$ & $590,800.07$ & $422,000.05$ \\
\hline La Calle & $23,200.00$ & & & \\
\hline La Crónica & $1,059,130.45$ & $1,059,992.93$ & $674,540.91$ & $400,000.00$ \\
\hline La Jornada & $580,000.00$ & $580,000.00$ & $232,000.00$ & \\
\hline La Opinión & & $20,880.00$ & $13,920.00$ & \\
\hline La Razón & $162,400.00$ & $116,000.00$ & & \\
\hline La Voz del Nevado & & $21,750.00$ & & \\
\hline
\end{tabular}




\begin{tabular}{lllll}
\hline La Voz Informativa & & $23,200.00$ & $23,200.00$ & $11,600.00$ \\
Marco Político & $278,400.00$ & $278,400.00$ & $278,400.00$ & $186,760.00$ \\
Mi Ambiente & $240,000.00$ & $280,000.00$ & $105,000.00$ & \\
Milenio & $1,740,000.00$ & $1,740,000.00$ & $1,100,000.00$ & \\
Noticias del Centro & & $34,800.00$ & & \\
Notimundo Informativo & $334,080.00$ & $334,080.00$ & $334,080.00$ & $194,880.00$ \\
Nuestra Zona & & $34,800.00$ & $46,400.00$ & $11,600.00$ \\
Ocho Columnas & $1,160,000.00$ & $1,160,000.00$ & $1,044,000.00$ & $580,000.00$ \\
OEM & $1,740,000.00$ & $1,740,000.00$ & $1,100,000.00$ & \\
Origen Mexiquense & $348,000.00$ & $348,000.00$ & $261,000.00$ & \\
Ovaciones & $1,160,000.00$ & $1,282,000.00$ & $954,000.00$ & $348,000.00$ \\
Perfil Urbano & & $40,000.00$ & & \\
Pódium & $40,000.00$ & $45,000.22$ & $50,000.00$ & \\
Portal & $229,680.00$ & $275,000.01$ & $137,500.00$ & \\
Publimetro & & $343,094.36$ & $357,901.59$ & \\
Puntual & $1,392,000.00$ & $1,276,000.00$ & $812,000.00$ & $580,000.00$ \\
Récord & $313,664.00$ & $278,864.00$ & $287,230.00$ & \\
Reporte Mexiquense & & & & $125,280.00$ \\
Veinticuatro 24 Horas & & $174,000.00$ & $365,400.00$ & \\
Vitral & & $139,200.00$ & $208,800.00$ & $121,800.00$ \\
Total & $\mathbf{2 3 , 8 6 4 , 8 0 1 . 1 3}$ & $\mathbf{1 8 , 1 5 5 , 4 4 2 . 2 4}$ & $\mathbf{5 , 7 2 0 , 6 3 6 . 8 9}$ \\
\hline
\end{tabular}

Tabla 1. Gasto en publicidad oficial -expresado en pesos mexicanos- en periodo no electoral/Comunicación Social GEM. Fuente: elaboración propia con base en la información provista por Saimex.

Las cifras anteriores fueron obtenidas a través del Sistema de Acceso a Información Mexiquense (Saimex) conjuntamente con los datos sobre principios o normas para la asignación de publicidad tanto en requisitos como adjudicación. En total se realizaron veinte solicitudes.

A nivel estatal, la Coordinación General de Comunicación Social (CGCS), posee un Manual General de Organización, publicado en la Gaceta Oficial de Gobierno el 3 de noviembre de 2015 , al que remite para explicar sus funciones y atribuciones presupuestales. Pero la realidad es que el documento sólo describe las facultades del Departamento de Planeación de la citada dependencia. No hay por tanto, una legislación estatal que enuncie a quiénes y porqué deben autorizarse o adjudicarse los fondos de la publicidad oficial, como tampoco existe un procedimiento o, en su caso, organismo que fiscalice el uso que se da a los recursos. 
En oposición, ha habido al menos una propuesta para regular el acceso a la publicidad oficial a cargo de la Asociación de Periodistas del Valle de Toluca (APVT), la Ley de Equidad Publicitaria, que no trascendió más que a la discusión en oficinas de diputados locales. Otras iniciativas legales: Ley para la Protección Integral del Ejercicio Periodístico del Estado de México, que no pasó al pleno de la Cámara mientras que hoy existe la promesa del gobernador entrante Alfredo del Mazo Maza (2017-2023) para impulsar la Ley de Protección a Periodistas del Estado de México. Aunque esta propuesta, como la anterior, están enfocadas a prevenir la condición de vulnerabilidad de los periodistas en su labor informativa más que a los asuntos publicitarios, tal como se confirma con el resto de las legislaciones en otros estados del país (Gómez, 2017).

Por lo demás, en materia de legislación, en la Constitución Política del Estado de México, en su Artículo 5, se hace mención al solo derecho de los mexiquenses a información pública y de protección de datos personales que al calce dice: "En su funcionamiento se regirá por los principios de certeza, legalidad, independencia, imparcialidad, eficacia, objetividad, profesionalismo, transparencia y máxima publicidad..." (artículo 5, Cámara de Diputados, 2017).

Asimismo, desde esta Constitución se remite a la Carta Magna de México para el ejercicio del derecho de la Libertad de Expresión y el que se deriva, la Libertad de Prensa, en sus artículos sexto y séptimo y el artículo 134 -adicionado en 2007- para instituir que

La propaganda, bajo cualquier modalidad de comunicación social, que difundan como tales, los poderes públicos, los órganos autónomos, las dependencias y entidades de la administración pública y cualquier otro ente de los tres órdenes de gobierno, deberá tener carácter institucional y fines informativos, educativos o de orientación social. En ningún caso esta propaganda incluirá nombres, imágenes, voces o símbolos que impliquen promoción personalizada de cualquier servidor público (Cámara de Diputados, 2017).

De forma contigua al marco legal constitucional mexicano, el Código Electoral del Estado de México señala en su artículo 70 a la radio y la televisión como los medios que "en ningún momento podrán contratar o adquirir, por sí o por terceras personas tiempos en cualquier modalidad" (CEEM, 2017) dejando sin efecto legal a la prensa.

Situación añadida es que, a partir de 2018, entra en vigor la reforma política que permitirá la reelección de alcaldes y diputados locales y, por tanto, el caldo de cultivo para que se prolonguen prácticas clientelares como acrecentar negocios o ganancias de los medios y sus propietarios desde los recursos públicos: "[El medio es] un negocio para sacar lana", asegura 
un periodista con casi medio siglo de experiencia, y agrega que por esa razón "una misma empresa, un mismo corporativo tiene este y luego otro y otro [negocio] porque así justifican entradas de dinero importantes para cada uno de sus medios, concentrados en un grupo".

Pero el privilegio de tener un medio va más allá, pues sus directivos y propietarios resuelven problemas fiscales, de financiamiento y de todo tipo: "Vamos a suponer, quiero construir un Sanatorio y quiero agilizar mis permisos; con mis relaciones lo hago. Ahorita te dije un Sanatorio, pero ponle el nombre que quieras a la otra empresa o a las otras empresas", sentencia el director de un medio asentado en Toluca.

\section{El fenómeno de los ayuntamientos}

Es a nivel municipal donde coexiste el dispendio de recursos públicos y, obviamente, a este ámbito se replica la ausencia de reglas o existe ambigüedad en los requisitos por cumplir. Como ejemplos, en la capital se pide "atender a los procesos de licitación y contratación pública" (Folio 00264/TOLUCA/IP/2016), en tanto que en Atlacomulco, además del registro ante el PNMI, que el medio sea "estrictamente profesional, donde su única labor será [sic] de informar de forma clara, eficiente y oportuna la información que se requiera dar a conocer por parte del ayuntamiento..." (Folio 00023/ATLACOM/IP/2016).

Un caso que contrasta con los anteriores es Tlalnepantla cuyas condiciones consisten en tener: 1. Registro como proveedor del ayuntamiento, 2. Registros ante Gobernación (Licitud de Título, Contenido, Derechos de Autor, Certificado), 3. Periodicidad, 4. Distribución, 5. Contenido, 6. Antigüedad, 7. Impacto en la Sociedad, 8. Penetración y 9. Cobertura de eventos -tipos- (Folio 00454/TLALNEPA/IP/2016).

Respecto de la publicidad con ayuntamientos, el director de un periódico regional del Valle de Toluca que circula de lunes a viernes señala que si bien los ingresos publicitarios del Gobierno del Estado son necesarios para los medios, "el mejor acuerdo es con ayuntamientos: “...15-20 mil pesos... pero métele, súmale varios municipios. Como dicen en tu tierra y en mi tierra: De granito en granito, llena el buche la gallina".

Por su parte, quien tiene a cargo la dirección de una publicación semanal que se edita en el Valle de México reconoce que "nunca ha habido un municipio con el que yo no trabaje porque tengo la calidad como para ser una buena [labor de vocero] de sus actividades".

Asegura que "todo el mundo desea estar publicado en [este medio] y hacemos, yo creo, que un trabajo plural en el que no atacamos; no somos ni izquierdosos ni nos clavamos a [sic] ninguna 
cuestión política. Simplemente al cliente lo tratamos con esmero, respetamos, le damos la forma cotidiana a sus notas para que sean lo más profesionales, sin tendencias informativas; lo que es, informativa...", concluye.

El tema del gasto oficial en publicidad oficial no queda en cantidad y subejercicio. Coexisten cifras negras o recursos de procedencia desconocida destinados a propietarios, directivos, periodistas o seudo periodistas a cambio de tratamiento informativo favorable al poder político, en el denominado "Chayote" y cuyo fenómeno converge en publicidad oficial indirecta.

Obviamente, se trata de un secreto a voces: ¿Las cantidades? "Decir que son 10, 20, 50 o 100, 200, 300 o 500 mil, eso sería hablar al aire", señala un periodista-columnista.

A su vez, el director de un medio regional asegura que "en la Secretaría General de Gobierno 'el chayito' va entre 50 [mil pesos] y poquito más de 50 [mil pesos] al mes. Tengo los nombres. Sí hay sobres amarillos y gorditos", asegura, aunque se niega a revelar datos concretos.

Pero también están los seudo periodistas o dueños de "pasquines" (Rosagel, 2009) quienes "reciben vales de gasolina de 100 pesos en varios gobiernos municipales... gente sin estudios, sin la preparación; con el periodiquito que sacan cada mes, cada 15 días...también acuden con los regidores y directores de área a pedirles su moche", reprocha un periodista director de medio regional. Así por tanto, al amparo de las relaciones y negocios se han constituido grandes fortunas, auspiciadas por el favor gubernamental.

En el Estado de México, los grandes capitales han estado ligados a familias, algunas de ellas con raíces de la época porfiriana, hasta que la apertura económica, la inversión extrajera y los nuevos modelos de negocios modificaron la estructura. Sin embargo, la incursión del poder político en los medios se daría desde Isidro Fabela en el periódico El Demócrata, una vez nombrado a cargo de la publicación su sobrino Gabriel Alfaro (Cruz, 2012).

A partir de entonces, ha prevalecido una suerte de relevancia económica y social de aquellas familias tradicionales lo mismo que de empresarios con origen nacional y extranjero. Destaca por un lado la familia Mena, propietaria de Grupo Heraldo y por el otro, Grupo Mac, Grupo Miled e Impresores Masel y Kakar cuyos dueños son de origen libanés. Han sido los últimos quienes registran un crecimiento exponencial dado su relación con exgobernadores.

Anuar Maccise, propietario de Grupo Mac, recibió el impulso a sus negocios desde el gobierno de Carlos Hank González, periodo en el que del sector comercial saltó al periodístico. Su hijo fungía hasta el 30 de abril del 2016 como integrante del Consejo de Administración de Genomma Lab, el laboratorio de los denominados productos milagro cuyo vicepresidente es Ramón Neme Sastre, hijo del exgobernador de Tabasco, Salvador Neme Castillo. 
El mayor crecimiento de Grupo Mac, hoy Capital Media, se dio de la mano del hoy presidente Enrique Peña Nieto y bajo la batuta de Luis Maccise, con la apertura de diarios en varias ciudades del país y la compra de estaciones de radio, afines en principio a las aspiraciones presidenciales de Peña Nieto y luego casi órganos de difusión de las actividades presidenciales. El consorcio mediático posee los periódicos Capital Toluca y Capital estado de México así como las revistas Cambio Estado de México y Cambio valle de México.

Por otro lado, edita once periódicos en igual número de estados, el diario de lunes a viernes Reporte Índigo, la versión mexicana de El País, The News, Cambio y Capital Mujer. Paralelamente, administra los diarios digitales: Capital Puebla y Capital Jalisco y los portales Efekto Noticias y Green TV; está también a cargo de 18 estaciones de radio, sin contar Radio Capital en Toluca, estado de México: Capital Máxima (seis estaciones), Capital FM POP (siete estaciones), Capital FM OLDIES (dos estaciones) y Capital Pirata FM (tres estaciones).

Con base en la herramienta de recopilación de datos Contratobook, "...entre enero del 2013 y diciembre del 2016, el gobierno de Enrique Peña Nieto otorgó a tres empresas de Grupo Mac Multimedia 156 contratos de publicidad oficial por un monto de 169 millones 271 mil pesos" (Fierro, 2017).

De otro lado se halla Grupo Miled que posee los periódicos $A B C$ de México, El Mañana de Toluca y El Vespertino, al interior del estado. Fuera del Estado de México, Miled Libien Kaui, propietario, tiene once periódicos en igual número de estados de la república mexicana, además de la revista Miled, y las concesiones de estaciones de radio en Toluca (98.9 FM), Atlacomulco (104.7 FM), Valle de Bravo (93.5 FM) y Tulancingo (97.1). Asimismo, administra el sitio http://miledmusic.com/ que reúne cien estaciones de radio. Miled Libien es a la par dueño de hoteles, estacionamientos, edificios (en obra negra) en Toluca y antaño de centros nocturnos y de entretenimiento.

En 2016 se señaló públicamente a Grupo Miled por sus adeudos de agua potable, pero el Ayuntamiento de Toluca descartó proporcionar información sobre este particular con el argumento de que son datos privados. Por otro lado, Grupo Miled mantiene sus instalaciones a unos pasos de las vías del tren aunque lo prohíbe Ley Reglamentaria del Servicio Ferroviario.

En lo que corresponde a Naim Libien Tella, vicepresidente de Impresores Masel S.A. de C.V., y Kakar Impresores S.A. de C.V. desde donde imprime Diario Amanecer, está acusado de defraudación fiscal y el Departamento del Tesoro de Estados Unidos lo investiga por presuntos vínculos con la delincuencia organizada de los cuales se ha dado cuenta a través de reportes periodísticos, principalmente El Universal. 
La sobrada dependencia económica hacia el presupuesto público, la propiedad y desarrollo de los medios la que se hace presente en el contenido informativo. Al respecto del análisis de contenido se llevó a cabo la revisión de 799 textos informativos desde 44 variables cada uno a partir de la herramienta de análisis del rol de los periodistas frente a la información de Claudia Mellado (2014). Así por tanto, los tópicos de la prensa mexiquense son del 62 al 97 por ciento de los casos de estudio sobre acciones del poder político en los ámbitos estatal, municipal y de la Legislatura. En cuanto al origen de la información, las fuentes son: 1. El gobernador, 2. Alcaldes, 3. Funcionarios estatales, 4. Funcionarios municipales y 5. Legisladores, tal cual se muestra en la figura que sigue. 


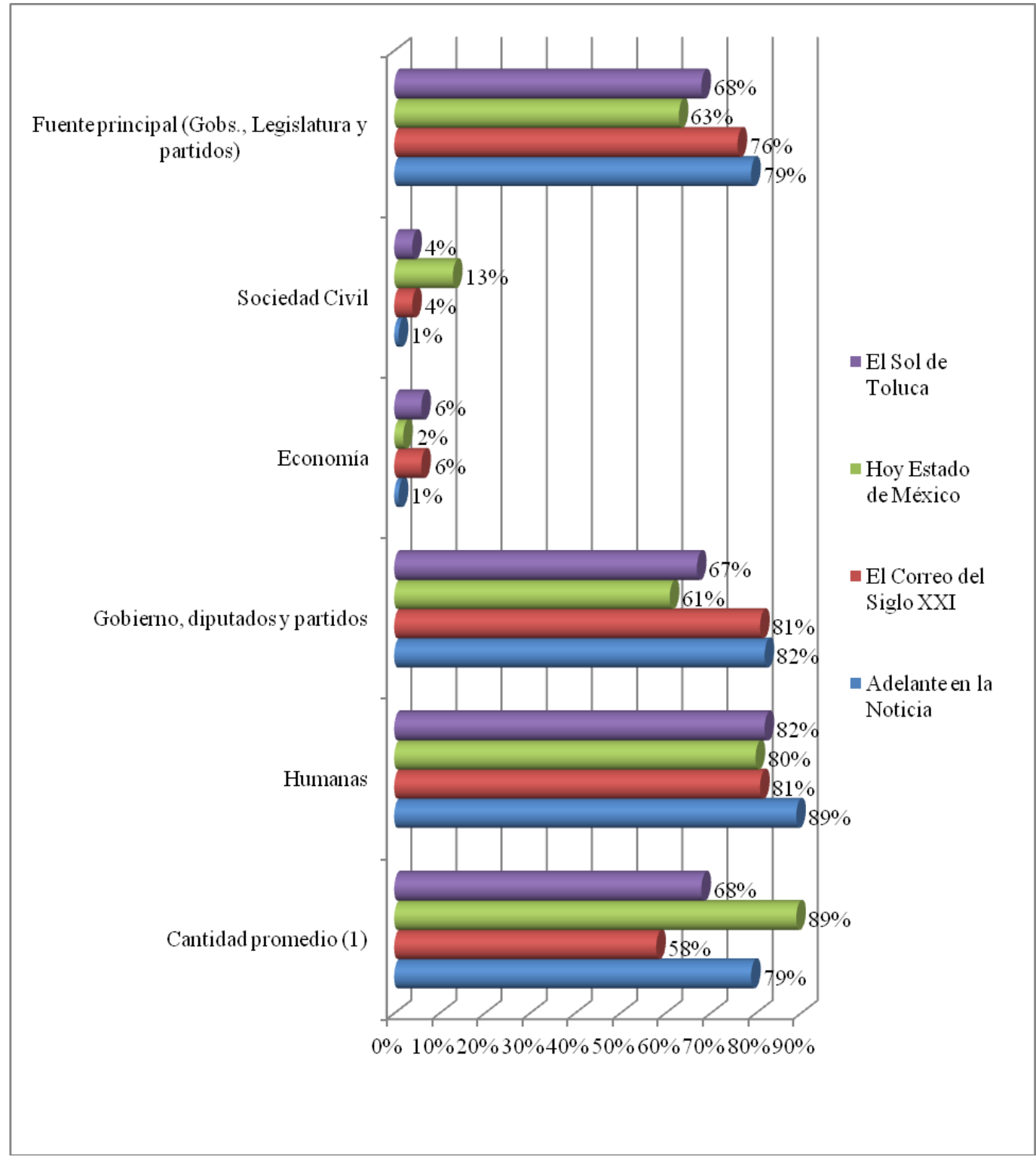

Figura 1. Fuentes de información de la prensa mexiquense

Fuente: elaboración propia con base en los resultados del análisis de contenido.

\section{Discusión}

La forma y maneras de la prensa del Estado de México o hallazgo y expresión del clientelismo mediático en el sistema de prensa mexiquense se advierte desde la mayor asignación del presupuesto publicitario, por más de un millón de pesos al mes, a tres periódicos de referencia 
nacional seguidos de medios estatales para integrar en conjunto un grupo de 19 medios privilegiados. En tanto, el resto de los medios impresos, que según la lista oficial oscila en cien, obtiene cada uno como cifra menor 15 mil pesos en el mismo periodo. En esta distribución se percibe arbitrariedad en la adjudicación de recursos pues la mayor parte se va a medios de fuera del estado y el resto a publicaciones locales y en ambos casos sin criterios formales más que el citado Manual General de Organización de la Coordinación General de Comunicación Social que no trata el tema aunque lo esgrima esta oficina a través de transparencia.

En tanto, a nivel de ayuntamientos el fenómeno de la publicidad oficial se reproduce y es en los municipios donde los medios logran más o mejores recursos ya que procuran varios acuerdos. En esta dirección, los medios de prensa se convierten en un negocio político para los propietarios pues su cliente principal son miembros del poder y esto se refleja en sus textos informativos a base de gacetillas, boletines, inserciones y notas reporteadas por los periodistas donde las fuentes de información son actores de la política, fundamentalmente el gobernador y presidentes municipales. Son pues en el sentido de la propiedad de los medios, la manera en que se comercializan, el intervencionismo que ejerce en ellos el poder político y el contenido político de las publicaciones (Hallin y Mancini, 2004) factores estructurales que inciden en su razón de ser y hacer.

No obstante, en el escenario mexicano el clientelismo mediático subyace a tales estructuras con prácticas que revelan corrupción. Así, por tanto, la relación histórica prensa-Estado en México ha perdurado más de un siglo con la subvención de recursos oficiales, extraoficiales, a modo de picaporte y ahora en el espacio virtual con recursos adicionales a medios y periodistas (Maldonado, Ramírez y Cárdenas, 2015).

Alrededor de lo anteriormente expuesto, la necesidad de legislar la publicidad oficial ha sido reiterada desde principios de este siglo y así como en la Cámara de Diputados se hayan al menos una decena de iniciativas de ley, de manera pública organizaciones no gubernamentales como Fundar Centro de Análisis e Investigación (http://fundar.org.mx/) (que anticipa un gasto global sexenal de 60 mil millones de pesos para situar a la presente administración como la de mayor sobre ejercicio presupuestal) y Article 19 (https://www.article19.org/) (quien interpuso una solicitud de amparo por la omisión del Congreso de la Unión al no legislar en torno al tema y la SCJN falló a su favor) han sido persistentes en el tema desde su labor de defensa de la Libertad de Expresión y Derecho a la Información.

Destacan en ambas sus propuestas generales de reducir el monto del gasto en publicidad; evitar el sobre ejercicio presupuestal; frenar la promoción personalizada y fomentar la 
transparencia y rendición de cuentas. Paralelamente, entidades internacionales entre los que se encuentra la Organización de Estados Americanos alberga principios de regulación de la publicidad oficial desde su análisis de la experiencia internacional en reglamentación publicitaria: 1. Establecer objetivos, contratación, asignación y control de la publicidad oficial, 2. Determinar lineamientos en las etapas de producción, contratación, distribución y control del avisaje del sector público y privado costeado con fondos públicos, 3. Evitar la discriminación de medios en función de su línea editorial u opiniones vertidas en estos. 4. Disponer de mecanismos de contratación ante situaciones de emergencia y extrema emergencia, 5. Permitir que especialistas técnicos intervengan en la definición de la pauta publicitaria y 6 . Especificar la selección de agencias de publicidad $u$ otros subcontratistas y 7 . Fijar sanciones apropiadas para la violación de las disposiciones.

No obstante, la urgencia de legislar mantiene frente a la pared al Congreso de la Unión se hace indispensable enfatizar en la asignación de publicidad oficial en función de la oferta y demanda de medios y/o la interacción y competencia de los medios en el mercado; establecer pautas para prevenir o dirimir conflictos de interés entre la gestión empresarial y la labor periodística y llevar a cabo estudios de consumo y preferencias de la audiencia.

\section{Conclusiones}

La ausencia histórica de una ley publicitaria en México ha dado pauta a acciones arbitrarias y clientelares del gasto público en cuanto a publicidad se refiere y esto ocurre también en periodos no electorales como en este estudio se corroboró. Han sido el abuso de funciones, tráfico de influencias, colusión y soborno los hechos que desde la prensa han denigrando aún más el panorama de la corrupción en México. De ahí que deban evitarse lagunas jurídicas en la nueva legislación obligatoria tomando en cuenta situaciones prácticas como las que ocurren en el enclave del partido hegemónico nacional y microcosmos geográfico de México, el Estado de México.

Por otro lado, debe procurarse mayor concientización y participación ciudadana en el conocimiento de sus derechos y obligaciones en materia de medios de comunicación y ahora internet, pues la continuidad de una prensa maniatada por el poder político en lo económico e informativo a través de la red de redes significa la prolongación de una prensa mantenida y a favor de las causas oficiales a través de los impuestos que pagan indirectamente los contribuyentes desde el menor de sus consumos. 
Pero también es indispensable reforzar las tareas de profesionalización del periodismo para evitar que la condición de vulnerabilidad económica de los periodistas sea factor de clientelismo mediático además de revisar su rol en la propiedad o cadena de mando de los medios pues su labor informativa y de interés editorial en el Estado de México continúa supeditada a intereses económicos y desde luego, políticos.

Aparte, medios, dueños y/o directivos y periodistas se han acostumbrados a no ser fiscalizados ni sancionados; su labor informativa al servicio al poder les ha procurado una vida de ventaja, impunidad y corrupción, contribuyendo así la prolongación del poder establecido en dirección opuesta a la democracia, responsabilidad social y respeto a la Libertad de Expresión. La ley que regule la publicidad ya es inexcusable como debe serlo su aplicación.

\section{Bibliografía}

Avilés, R. (2007). La censura al periodismo en México: Revisión Histórica y Perspectivas. Razón y Palabra, 12(59), Instituto Tecnológico y de Estudios Superiores de Monterrey. Recuperado de http://www.razonypalabra.org.mx/anteriores/n59/raviles.html

Benavides, J. (2009). Gacetilla. Media, Culture \& Society, 22, 85-104. doi/abs/10.1177/016344300022001005

Carreño, J. (2000). Cien años de subordinación. Un modelo histórico de la relación entre prensa y poder en México en el siglo. Recuperado de http://www.saladeprensa.org/art102.htm

Combes, H. (enero-mayo, 2011). ¿Dónde estamos con el estudio del clientelismo? Desacatos, 36 13-32.

Recuperado de http://desacatos.ciesas.edu.mx/index.php/Desacatos/article/view/301/181

Constitución Política de los Estados Unidos Mexicanos (2017). Recuperado de http://www.diputados.gob.mx/LeyesBiblio/pdf/1_240217.pdf

Constitución Política del Estado Libre y Soberano de México (2017). Recuperado de http://legislacion.edomex.gob.mx/sites/legislacion.edomex.gob.mx/files/files/pdf/ley/vig/l eyvig001.pdf

Cosío Villegas, D. (1972). El sistema político mexicano. Las posibilidades de cambio. Austin, Texas: Institute of Latin American Studies, the University of Texas at Austin.

Cruz Jiménez, F. (2012). Los Golden Boys. México: Planeta Mexicana. 
Fernández C. F. (1982). Los medios de difusión masiva en México. México: Juan Pablos. Fierro, J. O. (2017). Videgaray y Nuño vinculan sus marcas con Grupo Mac, consorcio de medios cercano a EPN. Aristegui noticias. Recuperado de https://aristeguinoticias.com/1403/mexico/videgaray-y-nuno-vinculan-sus-marcas-congrupo-mac-consorcio-de-medios-cercano-a-epn/

Fundar (2014). Comprando complacencia: Publicidad oficial y censura indirecta en México. México, USA, Francia: WAN-IFRA.

García, C. (2013). Radiografía de la prensa diaria en México en 2010. Comunicación y Sociedad, 20, 65-93. Recuperado de http://www.revistascientificas.udg.mx/index.php/comsoc/article/view/217/252

Gobierno del Estado de México (2016). Manual General de Organización de la Coordinación General de Comunicación Social. Recuperado de https://bit.ly/2GxB6ly

Gómez, E. (2017). Ley de Periodistas en el Estado de México: debate inconcluso. Métrica, periodismo y transparencia. Recuperado de http://metricadigital.com/leyes-deperiodistas-entre-derechos-ficticios-y-dadivas-sociales

Guerrero y Márquez, M. (2014). El modelo "liberal capturado" de sistemas mediáticos, periodismo y comunicación en América Latina. Temas de Comunicación, 29, 135-170.

Hallin y Mancini, P. (2004). Comparing Media Systems. Three Models of Media and Politics. United States: Cambridge University Press.

Lichfield, G. (2000). La declarocracia en la prensa mexicana. Letras Libres. Recuperado de http://www.letraslibres.com/mexico/la-declarocracia-en-la-prensa

Maldonado Pérez, P. (2017). Prensa y poder en el periodismo regional: La articulación del clientelismo mediático en el Estado de México (Tesis doctoral). Universidad Iberoamericana, Ciudad de México.

Maldonado Pérez, P.; Ramírez, L. G. y Cárdenas, A. (2015). Periodistas mexicanos, internet y poder político ante la discrecionalidad en la asignación de publicidad. Memorias AMIC, Estudios de Periodismo, 1686-1710. Recuperado de http://amic2015.uaq.mx/docs/memorias/GI_05_PDF/GI_05_Periodistas_mexicanos.pd

Mellado, C. (2014). Professional roles in news content: Six dimensions of journalistic role performance. Journalism Studies. DOI:10.1080/1461670X.2014.922276

Pfoh, E. (2005). La formación del estado nacional en América Latina y la cuestión del clientelismo político. Recuperado de https://bit.ly/2HfsCAL

Rodríguez C. R. (1993). Prensa vendida: una historia del periodismo mexicano y su vínculo con el poder. México: Grijalbo. 
Rodríguez Munguía, J. (2007). La otra guerra secreta. Los archivos de la prensa y el poder. México: Debate.

Roniger, L. (1994). Civil Society, Patronage and Democracy. International Journal of Comparative Sociology, 35, 207-220. Doi: 10.1163/002071594x00246

Roniger, L. (2004). Political Clientelism, Democracy, and Market Economy. Comparative politics, 36(3), 353-375.

Rosagel, S. (2009). Los pasquines del estado de México. Etcétera. Recuperado de https://bit.ly/2lzgEkN

Scherer, J. y Monsiváis, C. (2003). Tiempo de saber. Prensa y poder en México. México: Aguilar.

Schröter, B. (2010). Clientelismo político: ¿existe el fantasma y cómo se viste? Revista Mexicana de Sociología, 72(1). Recuperado de http://www.ejournal.unam.mx/rms/20101/RMS010000105.pdf

Trejo, R. (1995-1996). Prensa y gobierno: Las relaciones perversas. Comunicación y Sociedad, Universidad de Guadalajara, 35-55. 